\title{
Crescimento da parte aérea e produção de mandioca para mesa sob lâminas de irrigação
}

\section{Growth of the airline and table production for table under irrigation blades}

\author{
Agenor Nicoli Neto \\ Universidade Federal do Espírito Santo - Centro Universitário Norte do Espírito Santo \\ E-mail: agenornicoli@gmail.com \\ OrclD: https://orcid.org/0000-0001-6441-418X \\ Joabe Martins de Souza \\ Universidade Federal do Espírito Santo - Centro Universitário Norte do Espírito Santo \\ E-mail: joabenv@gmail.com \\ OrclD: https://orcid.org/0000-0003-0920-6446
}

Robson Bonomo

Universidade Federal do Espírito Santo - Centro Universitário Norte do Espírito Santo

E-mail: robson.bonomo@gmail.com

OrcID: https://orcid.org/0000-0002-4022-8216

Alex Campanharo

Universidade Federal do Espírito Santo - Centro Universitário Norte do Espírito Santo

E-mail: alexcampanharo@yahoo.com.br

OrclD: https://orcid.org/0000-0002-7108-6708

Alan de Lima Nascimento

Universidade Federal do Espírito Santo - Centro Universitário Norte do Espírito Santo

E-mail: alan-lima07@hotmail.com

OrclD: https://orcid.org/0000-0002-2174-7758

Resumo: É conhecido que o desenvolvimento radicular é reflexo das condições em que se encontra a parte aérea. Na cultura da mandioca, é esperado que quanto mais rápido for o desenvolvimento da parte aérea, mais rápido também será o crescimento radicular, e isso pode trazer precocidade na colheita dessa cultura. Objetivou-se o crescimento da parte aérea e produção de raízes tuberosas de mandioca para mesa, em São Mateus, ES. O delineamento experimental foi em blocos inteiramente casualizado, em esquema de parcela subdividida no tempo com quatro repetições. As parcelas consistiram de cinco níveis de água (T1 tratamento não irrigado; T2 - tratamento irrigado com reposição de $33 \%$ da ETc (evapotranspiração da cultura); T3 - reposição de $66 \%$ da ETc; T4 - reposição de 100\% da ETc; e T5 - com reposição de $133 \%$ da ETc). As subparcelas consistiram em três épocas (90, 180 e 300 DAE - dias após emergência) de medição de altura e diâmetro. As maiores produtividades de mandioca de mesa são alcançadas com lâmina de irrigação de $136 \%$ e $139 \%$ da ETc, para raiz total e comercial. As plantas com maiores lâminas de irrigação cresceram em altura e diâmetro e também produziram maior quantidade de raízes. Houve correlação positiva quando se verificou a relação entre a variável massa fresca da parte aérea (MFPA) com produtividade comercial (PC) e total (PT).

Palavras-Chave: Manihot esculenta Crantz; Manejo de irrigação; Crescimento vegetativo.

Abstract: The objective of this study was to increase the shoot and tuberous roots production of cassava to table, in São Mateus, ES. The experimental design was a completely randomized block design in a split-plot with four replications. The plots consisted of five water levels (T1 - non-irrigated treatment; T2 - irrigated treatment with 33\% ETc replacement (crop evapotranspiration); T3 - 66\% ETc replacement; T4 - 100\% ETc replacement; and T5 - with replacement of $133 \%$ of ETc). The subplots consisted of three times (90, 180 and $300 \mathrm{DAE}$ - days after emergence) of height and diameter measurement. The highest yields of table cassava 
are achieved with irrigation depth of $136 \%$ and $139 \%$ of ETc for root. total and commercial respectively, under the edaphoclimatic conditions studied in the northern state of Espirito Santo. Plants with larger irrigation depths grew faster in height and diameter and produced more. There was a positive correlation when the relationship between the variable fresh air mass (MFPA) and commercial (PC) and total (PT) productivity was verified.

Keywords: Manihot esculenta Crantz; Irrigation management; Vegetative growth.

Data de recebimento: $30 / 10 / 2019$

Data de aprovação: 16/06/2020

DOI: https://doi.org/10.30612/agrarian.v13i50.10598

\section{Introdução}

A mandioca (Manihot esculenta Crantz) tem a capacidade de se desenvolver em áreas pequenas e com menor precipitação. É cultivada principalmente em fazendas de pequena escala, geralmente consorciadas com outros vegetais. As raízes $(1-8 \mathrm{~kg})$ usadas principalmente para consumo humano são processadas em uma ampla variedade de alimentos tradicionais (PACHECO et al., 2020).

Porém o manejo da cultura, especifica para cada local, é o fator que determina a resposta produtiva das plantas de mandioca. O arranjo espacial, com a densidade de plantio ótima, depende do tipo de crescimento da planta (com ou sem ramificações laterais), bem como da disponibilidade hídrica, fertilidade do solo e sistema de cultivo (monocultivo ou consorciado) (SILVA et al, 2013, PEIXOTO et al., 2020).

A primeira manifestação biofísica da deficiência hídrica na planta é a redução do volume celular, dessa forma, as atividades que têm relação com a turgidez das folhas são afetadas em função da queda no potencial de água no solo. Um potencial déficit hídrico no solo não afeta somente a dimensão de folhas, também interfere negativamente no crescimento e nutrição da planta. É possível que as mesmas forças que interferem no crescimento foliar no período de estresse interferem também no desenvolvimento dos caules (TAIZ \& ZEIGER, 2013).

Outro problema da deficiência hídrica está relacionado com a absorção de nutrientes pela planta, que segue em maior parte juntamente com a água, dessa forma plantas em solos com altas tensões de retenção de água tendem a manifestar rapidamente uma deficiência nutricional. Segundo Ferreira et al. (2008), a disponibilidade de água no solo é muito importante por se tratar de um veículo que carreia os minerais até a interface solo-raiz e xilema.

É conhecido que o desenvolvimento radicular é reflexo das condições em que se encontra a parte aérea, ou seja, é dependente dos processos fisiológicos de fotossíntese. Assim sendo, tratando-se especificamente na cultura da mandioca, é esperado que quanto mais rápido for o desenvolvimento da parte aérea, mais rápido também será o crescimento radicular, e isso pode trazer precocidade na colheita dessa cultura. Dessa forma, objetivou-se avaliar a parte aérea e a produção de mandioca para mesa sob lâminas de irrigação.

\section{Material e Métodos}

O experimento foi conduzido na Fazenda Experimental do CEUNES, pertencente à Universidade Federal do Espírito Santo, município de São Mateus, latitude $18^{\circ} 43^{\prime} \mathrm{S}$, longitude $39^{\circ} 51^{\prime} \mathrm{W}$ e altitude média de 39 metros. O clima da região é quente e úmido (tipo Aw de Köppen), com estação seca no outono-inverno e estação chuvosa na primavera-verão (PEZZOPANE et al., 2010).

O solo foi classificado como ARGISSOLO AMARELO segundo Santos et al. (2013). O local do experimento possui topografia plana, tendo suas características físico-hídricas, incluindo a curva de retenção de água apresentadas na Tabela 1. 
Tabela 1. Características de textura, massa especifica (ME) e curva de retenção de água do solo da área experimental.

\begin{tabular}{cccccc}
\hline \multirow{2}{*}{$\begin{array}{c}\text { Camadas } \\
\mathbf{m}\end{array}$} & Areia & Silte & Argila & $\begin{array}{c}\mathbf{M E} \\
\mathbf{k g ~ d m}\end{array}$ & Equação da Curva de Retenção $^{\mathbf{3}}$ \\
\cline { 2 - 6 } & \multicolumn{5}{c}{$\mathrm{g} \mathrm{kg}^{-1}$} \\
\hline $0,00-0,20$ & 655 & 27 & 318 & 1,43 & $\left.\mathrm{U}=14,37+\left((9,70) /\left(1+(0,053 \Psi)^{1,328}\right)^{0,386}\right)\right)$ \\
$0,20-0,40$ & 655 & 27 & 318 & 1,65 & $\left.\mathrm{U}=19,11+\left((8,87) /\left(1+(0,0429 \Psi)^{1,929}\right)^{0,048}\right)\right)$ \\
\hline
\end{tabular}

${ }^{1} \mathrm{U}=$ umidade volumétrica $(\% \mathrm{v} / \mathrm{v}) ; \Psi=$ tensão matricial $(\mathrm{kPa})$.

Baseado na caracterização química do solo conforme Donagema et al. (2011). (Tabela 2) foi determinada a correção da acidez e elevação da saturação por base para $60 \%$, após 90 dias foi realizada as adubações de acordo com Prezzoti et al. (2007). No plantio, realizado em julho de 2015, foram aplicadas as doses recomendadas de fósforo e potássio, e as adubações nitrogenadas foram efetuadas em cobertura aos 20 e 60 dias após o plantio. As manivas utilizadas no plantio foram selecionadas buscando-se uniformizar o material utilizado. Foram utilizadas frações do terço médio das plantas, com comprimento de 0,20 m, e de 0,02 a 0,03 m de diâmetro.

Tabela 2. Análise química do solo da área experimental.

\begin{tabular}{|c|c|c|}
\hline Parâmetro Analisado & Unidade & Valor \\
\hline Fósforo Mehlich ${ }^{1}$ & $\mathrm{mg} \mathrm{dm}^{-3}$ & 7,0 \\
\hline Potássio $(K)^{1}$ & $\mathrm{mg} \mathrm{dm}^{-3}$ & 45,0 \\
\hline Enxofre $(S)^{3}$ & $\mathrm{mg} \mathrm{dm}^{-3}$ & 8,0 \\
\hline Cálcio $(\mathrm{Ca})^{4}$ & cmolc $\mathrm{dm}^{-3}$ & 1,5 \\
\hline Magnésio $(\mathrm{Mg})^{4}$ & cmolc $\mathrm{dm}^{-3}$ & 0,5 \\
\hline Alumínio (Al) ${ }^{4}$ & cmolc $\mathrm{dm}^{-3}$ & 0,3 \\
\hline $\mathrm{H}+\mathrm{Al} 5$ & cmolc $\mathrm{dm}^{-3}$ & 2,8 \\
\hline $\mathrm{pH} \mathrm{em} \mathrm{H}_{2} \mathrm{O}^{6}$ & - & 5,4 \\
\hline Matéria Orgânica 8 & dag $\mathrm{kg}^{-1}$ & 2,1 \\
\hline Ferro $(\mathrm{Fe})^{1}$ & $\mathrm{mg} / \mathrm{dm}^{-3}$ & 166 \\
\hline Zinco $(Z n)^{1}$ & $\mathrm{mg} \mathrm{dm}^{-3}$ & 0,2 \\
\hline Cobre $(\mathrm{Cu})^{1}$ & $\mathrm{mg} \mathrm{dm}^{-3}$ & 0,5 \\
\hline Manganês $(\mathrm{Mn})^{1}$ & $\mathrm{mg} \mathrm{dm}^{-3}$ & 5,0 \\
\hline Boro (B) 9 & $\mathrm{mg} \mathrm{dm}^{-3}$ & 0,58 \\
\hline Sódio $(\mathrm{Na})^{1}$ & $\mathrm{mg} \mathrm{dm}^{-3}$ & 21,0 \\
\hline Relação $\mathrm{Ca} / \mathrm{Mg}$ & - & 3,0 \\
\hline Relação Ca/K & - & 13,0 \\
\hline Relação Mg/K & - & 4,3 \\
\hline Sat. Ca na CTC (T) & $\%$ & 30,5 \\
\hline Sat. Mg na CTC (T) & $\%$ & 10,2 \\
\hline Sat. K na CTC (T) & $\%$ & 2,3 \\
\hline Índice saturação Na & $\%$ & 1,8 \\
\hline Soma de Bases (SB) & cmolc $\mathrm{dm}^{-3}$ & 2,2 \\
\hline CTC efetiva $(\mathrm{t})$ & cmolc $\mathrm{dm}^{-3}$ & 2,5 \\
\hline CTC a pH $7,0(\mathrm{~T})$ & cmolc $\mathrm{dm}^{-3}$ & 5,0 \\
\hline Sat. Alumínio (m) & $\%$ & 12,0 \\
\hline Saturação de bases & $\%$ & 44,1 \\
\hline
\end{tabular}

Durante a condução do experimento, foram realizadas três capinas manuais e uma química utilizando-se herbicida não seletivo a base de glifosato, e duas pulverizações, para o controle do ácaro (Mononychellus tanajoa), em todo o experimento, utilizando-se acaricida e inseticida de contato e ingestão do grupo químico das avermectinas, nos meses de abril e maio de 2016.

$O$ delineamento experimental foi em blocos inteiramente casualizados em esquema de parcela subdividida no tempo, com cinco parcelas, três subparcelas e quatro repetições. Nas quais as parcelas foram cinco níveis de suprimento de água sendo: T1 - tratamento não irrigado; T2 - tratamento irrigado com 
reposição de 33\% da ETc (evapotranspiração da cultura); T3 - 66\% da ETc; T4 - 100\% da ETc; e T5 - 133\% da ETc. As subparcela consistiram em três época de medição de altura e diâmetro, sendo aos 90, 180 e 300 DAE - dias após emergência, e a colheita foi realizada aos 9 MPE (meses pós-emergência) (abril/2016).

A cultivar plantada foi a conhecida como aipim manteiga, empregada para mesa, arranjadas em fileira dupla $(1,5 \mathrm{~m} \times 1,0 \mathrm{~m} \times 0,6 \mathrm{~m})$. As parcelas compreenderam duas fileiras duplas com um comprimento total de $8,0 \mathrm{~m}$, e largura de $5,2 \mathrm{~m}$, com 13 plantas por linha na parcela e um total de 52 plantas. As subparcelas (época de colheita) consistiram na colheita de oito plantas por parcela. O sistema de irrigação empregado foi por microaspersão com a linha de microaspersores posicionada entre as duas fileiras duplas.

A evapotranspiração de referência (ETo) foi determinada, segundo Allen et al. (1998), por meio de medidas dos elementos velocidade do vento $\left(\mathrm{m} \mathrm{s}^{-1}\right)$, radiação solar $\left(\mathrm{MJ} \mathrm{m}^{-2} \mathrm{dia}^{-1}\right)$, umidade relativa do ar e temperatura do $\operatorname{ar}\left({ }^{\circ} \mathrm{C}\right)$, obtidos em uma estação meteorológica automática da rede do INMET instalada próxima ao local.

Os valores de Kc empregados, para cada fase de desenvolvimento das plantas, nas estimativas da evapotranspiração da cultura $(\mathrm{ETc}=\mathrm{ETo} \mathrm{Kc}, \mathrm{mm}$ dia-1) foram 0,30 do plantio aos $30 \mathrm{DAE}$, crescentes até a fase 03, e 0,80 (fase 03) até a colheitas, baseados nos valores apresentados por Coelho Filho et al. (2009). A lâmina de irrigação aplicada foi determinada pela Eq.1.

$$
L a=(E T c \times L A P)-P
$$

Em que: La = lâmina de irrigação localizada, $(\mathrm{mm})$; ETc = evapotranspiração da cultura (ETo x Kc), $\mathrm{mm} ; \mathrm{LAP}=$ fração da lâmina aplicada em cada parcela, em decimal; $\mathrm{P}=$ precipitação no período, $\mathrm{mm}$.

O turno de rega adotado foi variável com irrigações realizadas sempre antes que fosse consumido $50 \%$ da capacidade real de armazenamento de água do solo - CRA (BERNARDO et al., 2006), considerando uma profundidade efetiva do sistema radicular de 0,30 $\mathrm{m}$ e capacidade de retenção de água no solo conforme tabela 2.

Os parâmetros avaliados na colheita foram: a) Massa fresca da parte aérea (MFPA) - determinado pela pesagem do material vegetal fresco logo após a colheita das raízes de cada parcela; b) produtividade de raízes tuberosas comerciais $(\mathrm{PC})$ - relação entre a massa de todas as raízes tuberosas comerciais produzidas na parcela pela área da mesma, (foram consideradas raízes comerciais aquelas com comprimento e diâmetro maior ou igual a $0,20 \mathrm{~m}$ e $0,03 \mathrm{~m}$, respectivamente), e produtividade total (PT) considerando todas as raízes. Já os parâmetros avaliados durante a condução do experimento foram: a) altura média das plantas - medida a partir do nível do solo até a extremidade mais alta da planta, em duas plantas por parcela; b) diâmetro do caule - medido com paquímetro a uma altura de $0,20 \mathrm{~m}$ do solo.

Os resultados obtidos foram submetidos à análise de variância, com desdobramento dos efeitos, segundo sua significância. A escolha do modelo de regressão baseou-se no modelo de maior grau significativo pelo teste $\mathrm{F}$, cujo desvio da regressão tenha sido não significativo. Para análise das épocas de colheitas foi utilizado teste de Tukey a $5 \%$ de probabilidade.

\section{Resultados e Discussão}

Os valores de precipitação total, coeficiente da cultura $(K c)$, evapotranspiração da cultura (ETc) e lâminas de água aplicadas, em função dos tratamentos, durante o período experimental, compreendido entre o plantio em 06/07/2015 até 28/04/2016, estão apresentados na Tabela 3. Os valores de precipitação observados nesse intervalo de tempo que corresponde a um período próximo de um ano, estão muito abaixo do esperado para o município de São mateus, pois o periodo das "águas" terminaram e a média anual é 1225 $\mathrm{mm}$.

Tabela 3. Precipitação, Coeficiente de cultivo (Kc), Evapotranspiração da cultura (ETc), e consumo mensal bruto de água de irrigação para cada um dos tratamentos de lâminas de irrigação.

\begin{tabular}{|c|c|c|c|c|c|c|c|}
\hline \multirow{2}{*}{ Meses } & \multirow{2}{*}{$\begin{array}{l}\text { Precipitação } \\
\text { (mm) }\end{array}$} & \multirow{2}{*}{ Kc } & \multirow{2}{*}{$\begin{array}{l}\text { ETc } \\
(\mathrm{mm})\end{array}$} & \multicolumn{4}{|c|}{ Lâminas de Irrigação (mm) } \\
\hline & & & & $33 \%$ & $66 \%$ & $100 \%$ & $133 \%$ \\
\hline $\mathrm{jul} / 15^{*}$ & 39,8 & 0,3 & 21,2 & 1,7 & 3,4 & 5,1 & 6,9 \\
\hline ago/15 & 65,2 & 0,5 & 44,5 & 8,7 & 17,5 & 26,2 & 35,0 \\
\hline set/15 & 4,4 & 0,6 & 89,3 & 30,9 & 61,7 & 92,6 & 123,4 \\
\hline
\end{tabular}




\begin{tabular}{cccccccc} 
out/15 & 35,8 & 0,8 & 112,4 & 28,6 & 57,1 & 85,7 & 114,3 \\
$\mathrm{nov} / 15$ & 26,6 & 0,8 & 130,9 & 35,1 & 70,3 & 105,4 & 140,5 \\
$\mathrm{dez} / 15$ & 34,4 & 0,8 & 154,4 & 39,4 & 78,8 & 118,3 & 157,7 \\
$\mathrm{jan} / 16$ & 193,8 & 0,8 & 114,9 & 0,0 & 0,0 & 0,0 & 0,0 \\
$\mathrm{fev} / 16$ & 6,2 & 0,8 & 135,6 & 44,8 & 89,7 & 134,5 & 179,4 \\
$\mathrm{mar} / 16$ & 52,6 & 0,8 & 128,8 & 26,9 & 53,7 & 80,6 & 107,4 \\
abr/16 & 27,4 & 0,8 & 100,1 & 17.7 & 35.4 & 53.1 & 70,8 \\
\hline Totais & 486,2 & & 1032,1 & 233,8 & 467,7 & 701,5 & 935,4 \\
\hline
\end{tabular}

Totais $\frac{486,2}{{ }^{*} \text { Plantio realizado em 06/07/2015; Colheita: 28/04/2016. }}$

Pode-se observar na Tabela 4 que se tem uma correlação positiva moderada quando se correlaciona massa fresca da parte aérea (MFPA) com produtividade comercial (PC) e produtividade total (PT). Esse resultado possibilita afirmar que a MFPA influencia diretamente os resultados de produtividade em geral. Em relação à altura de plantas (ALT), percebe-se que não há nenhuma correlação da mesma com as demais variáveis. Boerboom (1978) encontrou correlação positiva entre a massa seca da planta inteira e das raízes de armazenamento, ou seja, existe forte relação positiva entre o peso seco da planta inteira com o peso seco das raízes tuberosas.

Tabela 4. Correlação simples das variáveis Massa fresca da parte aérea (MFPA) e Altura de plantas (ALT) sobre a produtividade comercial (PC) e produtividade total (PT).

\begin{tabular}{ccc}
\hline Variável & PC & PT \\
\hline MFPA & $0,48^{*}$ & $0,53^{*}$ \\
ALT & $0,30 \mathrm{~ns}$ & $0,38 \mathrm{~ns}$ \\
\hline
\end{tabular}

ns não significativo. * significativo a $5 \%$ de probabilidade pelo teste de $\mathrm{t}$.

Na Tabela 5 pode-se verificar as informações sobre os dados da análise de variância de cada variável. Verifica-se que somente os resultados da massa fresca da parte aérea não tiveram diferença entre os tratamentos, isso pode ser explicado pela ocorrência da interferência de alguns eventos climáticos, ou seja, acredita-se que o tratamento não irrigado após a grande precipitação pluviométrica no mês de janeiro (Tabela 3) teve um rápido crescimento vegetativo, a ponto de se igualar aos demais em termos de massa verde, já que estes iniciaram o processo de senescência e queda de folhas mais cedo.

Em termos numéricos, os tratamentos apresentaram produtividades de massa de parte aérea em média ao redor de 19,8 $\mathrm{Mg} \mathrm{ha}^{-1}$ com estande de plantas de 13.3 plantas ha- $^{-1}$. Mesmo não ocorrendo diferença na parte aérea, verifica-se que em termos de produtividade constatou-se diferença, sendo explicado em razão de que a planta não irrigada não teve tempo suficiente para converter toda energia absorvida pela fotossíntese em produção de raízes, a ponto de destacar o aumento na produtividade, já que, o período entre a fase de grandes precipitações e a colheita foi relativamente curto.

De acordo com Lessa (2019), em estudo avaliando a produtividade de parte aérea de oito genótipos de mandioca avaliado em diferentes períodos no Recôncavo da Bahia com um estande de 16.666 plantas ha-1, encontrou aos 8 meses após plantio na média 20,3 $\mathrm{Mg} \mathrm{ha}^{-1}$, resultado bem semelhante ao encontrado nesse estudo. Tironi et al. (2014) encontraram resultados também parecidos de produtividade de parte aérea aos 8 meses após plantio, com valores de 21,8 Mg ha-1 e 20,3 Mg ha-1 para os cultivares Fepagro-RS13 e FepagroRS14 respectivamente, e com estande de 15.6 plantas ha $^{-1}$.

Tabela 5. Massa fresca da parte aérea (MPA); Produtividade Total (PT) e Produtividade Comercial (PC).

\begin{tabular}{|c|c|c|c|}
\hline Suprimento de água (\%ETc) & $\begin{array}{c}\text { MFPA } \\
\text { Mg ha }^{-1}\end{array}$ & $\begin{array}{c}\text { PT } \\
\text { kg ha-1 }^{-1}\end{array}$ & $\begin{array}{c}\mathrm{PC} \\
\mathrm{kg} \mathrm{ha}^{-1}\end{array}$ \\
\hline $\mathrm{NI}$ & $18,83 a$ & $15732,94 \quad b$ & 8658,117 \\
\hline 33 & $17,10 \mathrm{a}$ & $23361,92 \quad b$ & 12634,47 \\
\hline 66 & 20,78 a & 36232,43 a & $24284,60 \quad b$ \\
\hline 100 & 20,37 a & 41971,87 a & 33964,57 a \\
\hline 133 & $22,25 \mathrm{a}$ & 41540,63 a & $29041,78 a b$ \\
\hline
\end{tabular}


Médias seguidas de mesma letra na mesma coluna não diferem significativamente a $5 \%$ de probabilidade pelo teste de Tukey. NINão irrigado.

As curvas de crescimento das plantas em diferentes épocas de avaliações estão apresentadas na Figura 1. Nota-se que para o período inicial e final o comportamento que melhor descreve o crescimento de plantas foi quadrático, já no intervalo mediano o comportamento foi linear em função das lâminas de irrigação.
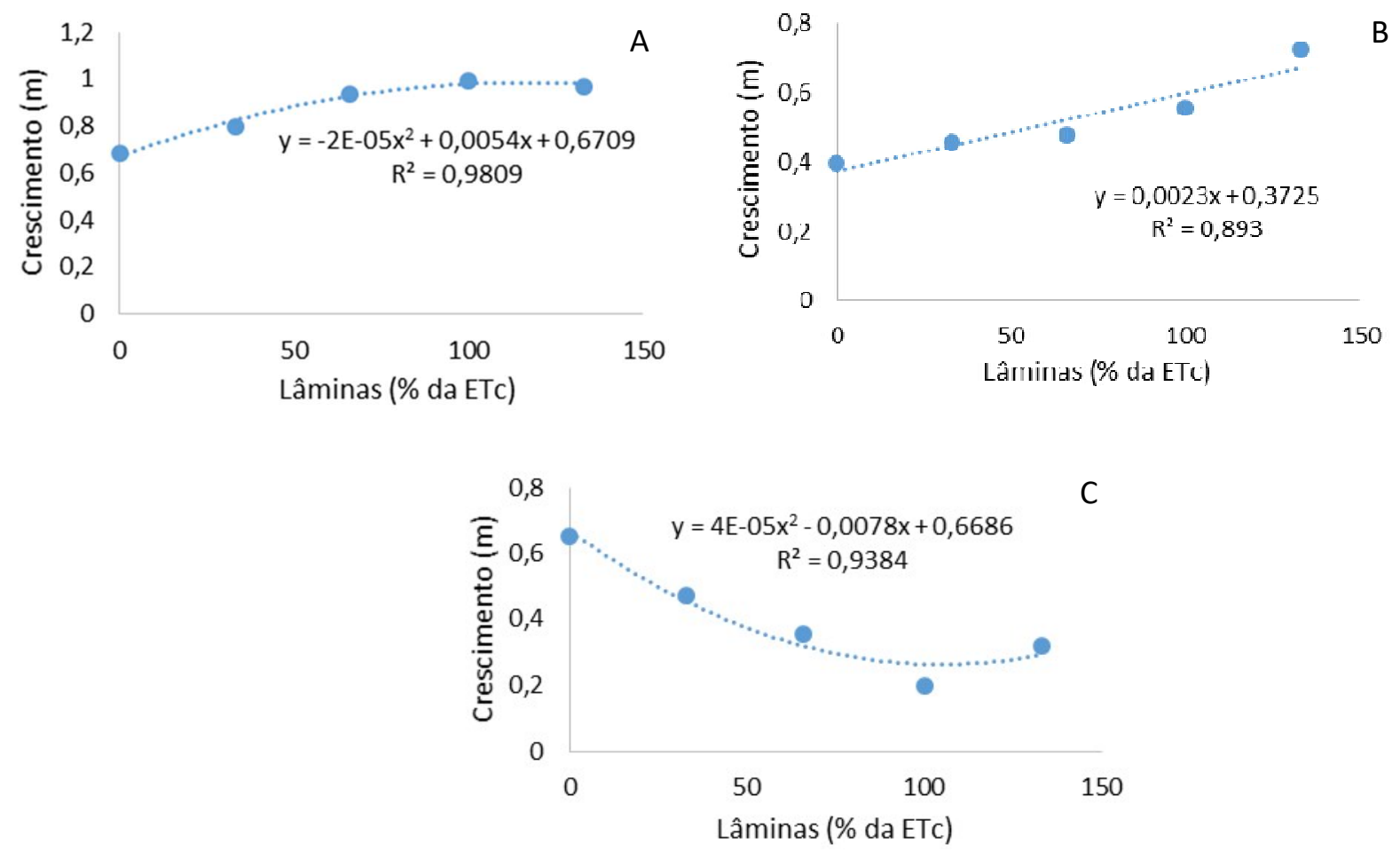

Figura 1. Crescimento das plantas acumulado até os 90 DAE (dias Após Emergência), (A); Crescimento das plantas acumulado no período de 90 a $180 \mathrm{DAE}$, (B) e Crescimento das plantas acumulado no período de 180 a $300 \mathrm{DAE},(\mathrm{C})$.

Em relação ao período de até $90 \mathrm{DAE}$, o ponto de máximo é obtido com uma lâmina de $135 \%$ da ETc, correspondendo ao crescimento de $1,04 \mathrm{~m}$, já se tratando do período mediano, sabe-se que essa é uma fase de rápido e intenso crescimento, e por isso a demanda por irrigação é alta, podendo-se destacar também que com maior lâmina de irrigação nesse período, é possível adiantar o crescimento vegetativo e, consequentemente, a produção de raízes, pois sendo assim, no último período que corresponde ao intervalo de 180 a 300 DAE o crescimento é menor, pelo fato de que a planta já cresceu vegetativamente o suficiente para sua produção e iniciou o processo de senescência das folhas. Por outro lado, se a reposição da ETc for menor durante os dois primeiros períodos, o crescimento acumulado na fase de 180 a 300 DAE é maior. Alves (2006) relata que o período entre 90 e 180 DAP (dias após plantio) é caracterizado como a fase de maior crescimento vegetativo na cultura da mandioca.

Trazendo para uma condição mais prática e exemplar, adotando-se a reposição da ETc de $135 \%$ em todos os períodos, pelo fato de corresponder a lâmina que proporcionou maior crescimento inicial e também porque está bem próxima da ETc que possibilitou maior produtividade comercial e total, tem-se uma altura total no período de 9 meses para a colheita de $2,07 \mathrm{~m}$.

Matos et al. (2016) analisando a produtividade de cultivares de mandioca sob déficit hídrico, encontraram valores de altura superiores em plantas sem estresse hídrico de cultivares desenvolvidos pela Embrapa Cerrados, colhidos aos 8 meses após plantio, sendo eles BRS 399; BRS 396; BRS 397; BRS 398, e com respectivas alturas de $2,54 \mathrm{~m} ; 2,48 \mathrm{~m} ; 2,33 \mathrm{~m} ; 2,80 \mathrm{~m}$.

Tironi et al. (2014) estudando o desempenho de cultivares de mandioca em ambiente subtropical, fazendo o manejo da irrigação de acordo com o balanço hídrico, observaram altura das plantas aos 8 meses de idade de 2,23 m; 2,19 m; 1,49 m; 1,44 m e 1,43 m para os respectivos cultivares: Fepagro-RS13; FepagroRS14; Cascuda; Fécula Branca e Estrangeira, respectivamente. 
Soares et al. (2017) em pesquisa avaliando os componentes agronômicos qualitativos e caracterização morfológica de variedades de mandioca em seis épocas de colheita, encontraram os maiores valores de altura referente ao período de 270 DAP (dias após plantio) de aproximadamente 1,40 m para a variedade roxinha e aos 330 DAP para a mesma variedade de $1,62 \mathrm{~m}$, pode-se notar que mesmo com tempo maior em campo, a altura foi inferior à mostrada nesse trabalho com a variedade manteiga, que por sua vez, foi colhida precisamente aos 297 dias após plantio.

Observando a Figura 2, nota-se que o comportamento da curva de crescimento para diâmetro da planta em cada fase é semelhante ao crescimento em altura, ou seja, mostrando que de modo geral a planta de mandioca cresce tanto em diâmetro quanto em altura seguindo uma curva gráfica similar. A porcentagem da ETc que proporcionou maior crescimento em diâmetro para as duas primeiras fases foram reposição de $100 \%$ da ETc, equivalendo a um crescimento de $0,17 \mathrm{~mm} \mathrm{dia}^{-1}$ até os $90 \mathrm{DAE}$ e $0,05 \mathrm{~mm}$ dia $^{-1}$ no intervalo de 90 a 180 DAE. Em relação ao último período, percebe-se que os tratamentos que receberam a lâmina de irrigação menor tiveram maior crescimento do diâmetro, isso pelo fato dos tratamentos com maiores lâminas de irrigação desenvolverem o diâmetro mais rapidamente até os 180 DAE.

Analisando o ciclo completo e adotando uma lâmina de $100 \%$ de reposição da ETc, tem-se um diâmetro de 21,47 mm, resultados semelhantes foi demonstrado por Soares et al. (2017), onde foi encontrado um diâmetro de $21,4 \mathrm{~mm}, 22,3 \mathrm{~mm}$ e $22,4 \mathrm{~mm}$ para a variedade Sergipe, Platinão e Pão da China respectivamente. Zanetti (2016) também encontrou diâmetro parecido com o relatado nesse trabalho, em torno de $21,0 \mathrm{~mm}$ aos 270 dias após plantio.
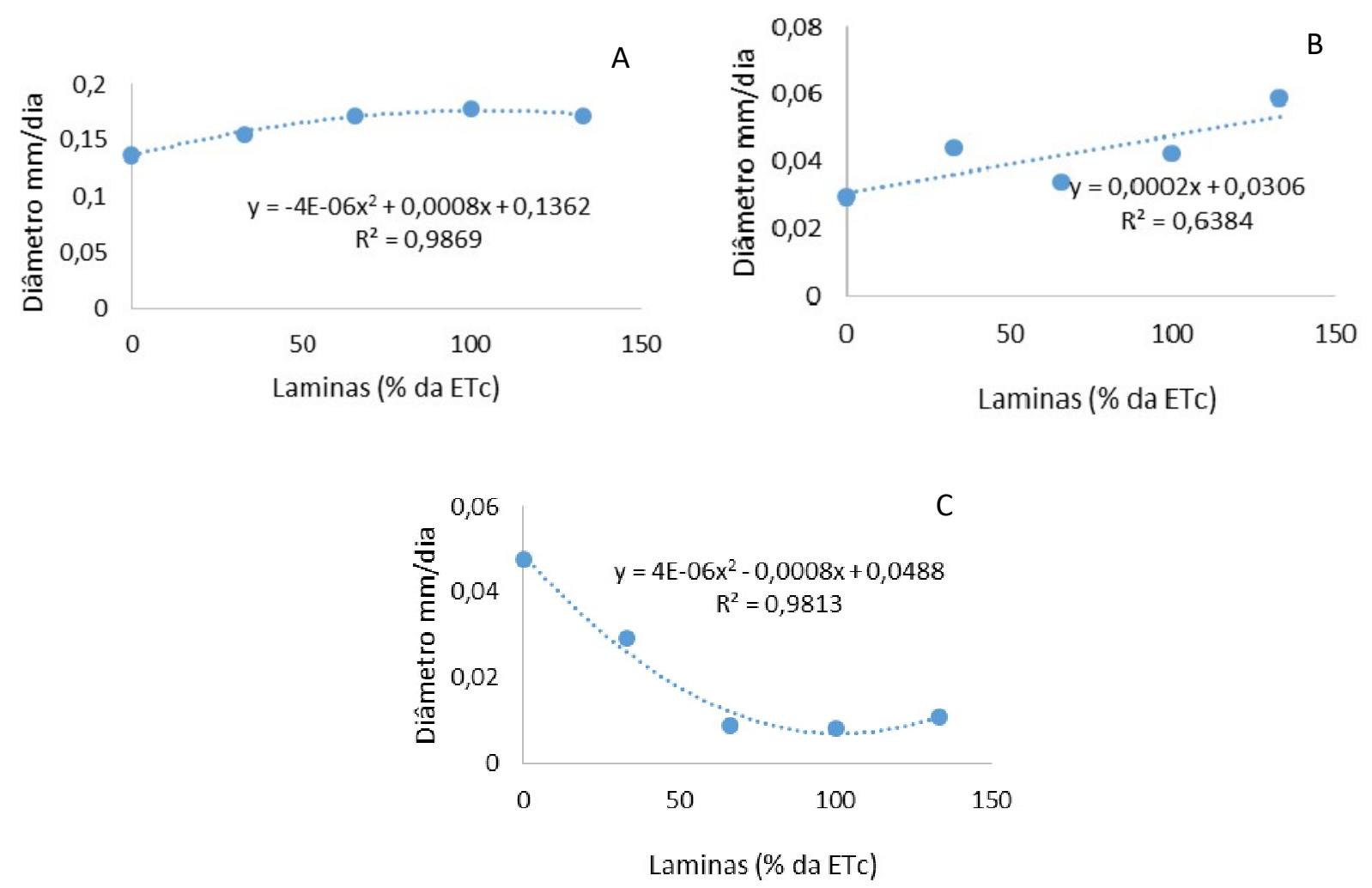

Figura 2. Crescimento do diâmetro das plantas até os 90 DAE (Dias Após Emergência), (A); Crescimento do diâmetro das plantas no período de 90 a $180 \mathrm{DAE},(\mathrm{B})$ e Crescimento do diâmetro das plantas no período de 180 a $300 \mathrm{DAE},(\mathrm{C})$.

Para produtividade comercial e total foi observado comportamento quadrático (Figura 3), sendo que, com 9 meses de idade tem-se potencial de produzir comercialmente $31.3 \mathrm{~kg} \mathrm{ha}^{-1}$, aplicando-se a lâmina de aproximadamente $139 \%$ da ETc. Em relação a produtividade total, o valor da lâmina é bem próximo, ficando em torno de $135 \%$ da ETc e condizendo a $42.4 \mathrm{~kg} \mathrm{ha}^{-1}$.

De acordo com Matos et al. (2016), a produtividade encontrada aos 8 meses de idade, para as cultivares BRS 399 e BRS 398 alcançaram 47,1 e 52,8 Mg ha-1, respectivamente. Tironi et al. (2014) registraram produtividades comerciais de 33,0 e 31,0 $\mathrm{Mg} \mathrm{ha}^{-1}$ para os cultivares Fepagro-RS13 e Fepagro- 
RS14, respectivamente, sendo que, são bem parecidas com a encontrada nesse trabalho, porém foram colhidas com 8 meses de idade.

Tavares et al. (2016) analisando a massa de raiz de diferentes cultivares de mandioca na região de Palmas - TO, constatou produtividade total aos 10 meses de idade equivalente a 44,0 $\mathrm{Mg} \mathrm{ha}^{-1}$ para a variedade Formosa, e já analisando a média de produtividade desses cinco cultivares, temos algo próximo a $37,8 \mathrm{Mg} \mathrm{ha}^{-1}$, resultado esse abaixo do encontrado nesse trabalho. Lessa (2014) em estudo sobre avaliação agronômica, seleção de genótipos e efeito de bordadura em experimento de mandioca no recôncavo da Bahia, encontrou produtividade total um pouco acima da relatada nesse trabalho, porem a colheita foi realizada aos 12 meses após plantio, onde chegou-se a 43,6 $\mathrm{Mg} \mathrm{ha}^{-1}$ para o genótipo BRS Tapioqueira, já aos 8 meses após plantio o mesmo genótipo produziu $17,0 \mathrm{Mg} \mathrm{ha}^{-1}$, cerca de $61 \%$ a menos.
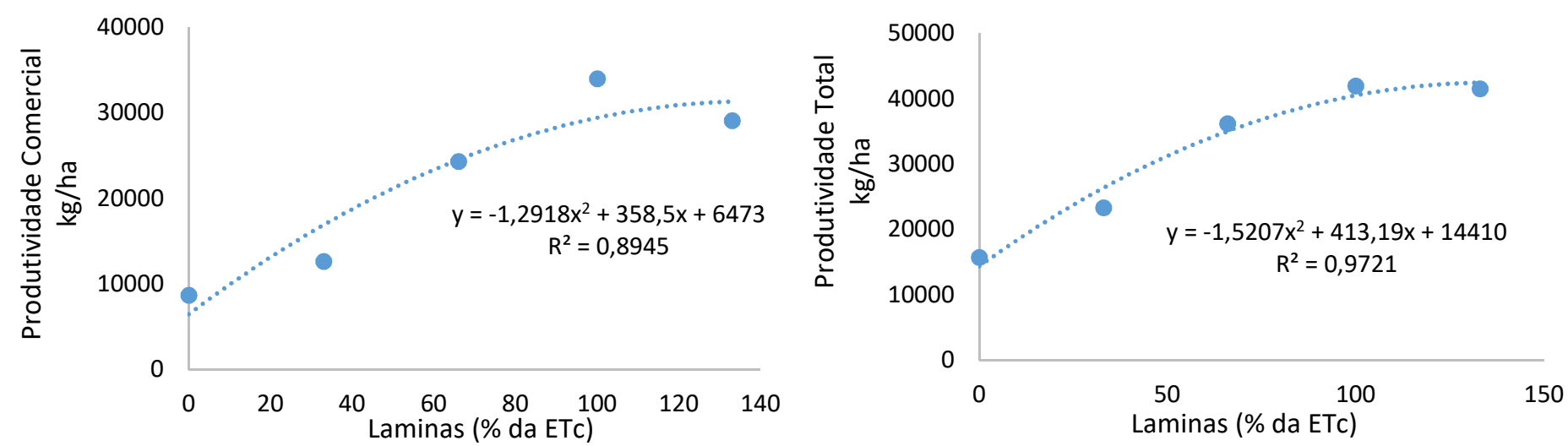

Figura 3. Produtividade comercial de raízes tuberosas de mandioca e produtividade total de raízes tuberosas de mandioca.

\section{Conclusões}

A produtividade da parte aérea não foi influenciada pelas lâminas de irrigação, porém a massa fresca da parte aérea correlacionou-se positivamente com a produtividade comercial e total de raízes

A maior produtividade comercial $\left(31.345 \mathrm{~kg} \mathrm{ha}^{-1}\right)$ foi obtida repondo $139 \%$ da ETc, e a menor reposição da ETc propiciou o menor crescimento vegetativo nas fases 1 e 2.

\section{Referências}

ALLEN, R.G.; PEREIRA, L.S.; RAES, D.; SMITH, M. Crop evapotranspiration: guidelines for computing crop water requirements. Roma: FAO, 1998. 300 p. (Irrigation and Drainage, n.56).

ALVES, A.A.C. Fisiologia da mandioca. In: Aspectos socioeconômicos e agronômicos da mandioca. Embrapa Mandioca e Fruticultura Tropical, Cruz das Almas, BA, v.7, p.138-169, 2006.

BERNARDO, S.; SOARES, A.A.; MANTOVANI, E.C. Manual de Irrigação. 8ed. Viçosa: UFV, 2006, 625p.

BOERBOOM, B.W.J.A Model of Dry Matter Distribution In Cassava (Manihot Esculenta Crantz). Dutch Journal of Agricultural Science, v.26, n.1, p.267-277, 1978.

COELHO FILHO, M.A.; SILVA, T.S.M.; GOMES JÚNIOR, F.A.; COELHO, E.F.; OLIVEIRA, V.V.M. Crescimento e evapotranspiração da cultura da mandioca solteira e consorciada em condições irrigadas. In: XVI Congresso Brasileiro de Agrometeorologia, Belo Horizonte, MG, 2009 - Minas Centro, Belo Horizonte, MG. Anais ... Belo Horizonte, MG, 2009.

DONAGEMA, G.K.; CAMPOS, D.V.B.; CALDERANO, S.B.; TEIXEIRA, W.G.; VIANA, J.H.M. Manual de métodos de análise de solo. 2. ed. rev. Rio de Janeiro: Embrapa Solos, 2011. 225 p.

FERREIRA, V.M.; MAGALHAES, P.C.; DURAES, F.O.M.; VASCONCELLOS, C.A.; ARAUJO NETO, J.C. de. Acúmulo e distribuição de macronutrientes em dois híbridos duplos de milho, em função da disponibilidade de água no solo. Revista Brasileira de Milho e Sorgo, v. 7, n. 1, p. 1-17, 2008. 
LESSA, L.S.; LEDO, C.A.S.; SANTOS, V.S. Effect of harvesting times on agronomic characteristics of industrial cassava genotypes. Revista Brasileira de Ciências Agrárias, v.14, n.2, e5647, 2019.

MATOS, F.S.; FELICIO, R.; SILVA, L.M.; NASCENTE, A.C.S.; CUSTÓDIO, J.P.C.; GUIMARÃES, R.R.; SANTOS, P.G.F.; SILVEIRA, P.S. Produtividade de cultivares de mandioca sob déficit hídrico. Agrienvironmental sciences, v. 2, n.1, p. 15-24, 2016.

PACHECO, R.I.L.; MACIAS, M.P.; CAMPOS, F.C.F.; IZQUIERDO, A.J.R; IZQUIERDO, G.A.R. Agronomic and physiological evaluation of eight cassava clones under water deficit conditions Revista Facultad Nacional de Agronomía, Medellín, v. 73, n. 1, p. 9109-9119, 2020.

PEIXOTO, I.G.G.; SOUSA, L.M.S.; MELO e SILVA, L.; NASCIMENTO, C.M.; SILVA, A.M.C.; ANCHIETA, O. F.A.; PRATA, R.C.; SILVA, J. Produção de mandioca irrigada em diferentes localidades e manejos no estado do Rio Grande do Norte, Brasil. Brazilian Journal of Development, Curitiba, v. 6, n.6, p.37078-37085, 2020.

PEZZOPANE, J.R.M.; CASTRO, F.S.; PEZZOPANE, J.E.M.; BONOMO, R.; SARAIVA, G.S. Zoneamento de risco climático para a cultura do café Conilon no Estado do Espírito Santo. Revista Ciência Agronômica, Ceará, v.41, n.3, p.341-348, 2010.

PREZOTTI, L.C.; GOMES, J.A.; DADALTO, G.G.; OLIVEIRA, J.A. Manual de Recomendação de Calagem e Adubação para o Espírito Santo - 5a aproximação. Vitória: SEEA/INCAPER/CEDAGRO, 2007. 305 p.

SANTOS, H.G.; JACOMINE, P.K.T.; ANJOS, L.H.C.; OLIVEIRA, V.A.; OLIVEIRA, J.B.; COELHO, M.R.; LUMBRERAS, J.F.; CUNHA, T.J.F. (Ed.). Solos: Sistema Brasileiro de Classificação de Solos. 5.ed. Brasília: Embrapa Informação Tecnológica, Rio de Janeiro: Embrapa Solos, 2018. 356 p.

SILVA, T.S.; BRAGA, J.D.; SOUSA, R.P.; LIMA e SILVA, P.S.; SILVEIRA, L.M. Planting density and yield of cassava roots. Revista Ciência Agronômica, Fortaleza, v. 44, n. 2, p. 317-324, 2013.

SOARES, M.R.S.; NASCIMENTO, R.M.; VIANA, A.E.S.; CARDOSO, A.D.; BRAGA, G.C.M.; FOGAÇA JÚNIOR, J.N.L. Componentes agronômicos qualitativos e caracterização morfológica de variedades de mandioca (Manihot esculenta Crantz) em seis épocas de colheita. Scientia Plena, v. 13, n. 6, p.1-12, 2017.

TAIZ, L; ZEIGER, E. Fisiologia vegetal. 5 ed. Porto Alegre: Artmed, 2013, 918 p.

TAVARES, K.M.; VIEIRA, J.C.; LIMA, T.M.; SOUSA, M.K.; SILVA FILHO, J.E.M.; MURAISHI, C.T. Análise de peso de raiz de diferentes cultivares de mandioca (Manihot esculenta) na região de Palmas-TO. Revista integralização universitária, v.11, n.14, p.32-36, 2016.

TIRONI, L.F.; UHLMANN, L.O.; STRECK, N.A.; SAMBORANHA, F.K.; FREITAS, C.P.O.; SILVA, M.R. Desempenho de cultivares de mandioca em ambiente subtropical. Bragantia, v. 74, n. 1, v.74, n. 1, p.58-66, 2015.

ZANETTI, S. Caracterização morfológica e nutricional em diferentes estádios fenológicos da mandioca de mesa IAC 576-70 sob deficiência hídrica. 2016. 72 f. Dissertação (Mestrado em Agronomia (Agricultura))

- Faculdade de Ciências Agronômicas da Unesp- Campus de Botucatu - SP, 2016. 